\title{
Comparative Cost-Effectiveness Analysis of Two MSF Surgical Trauma Centers
}

\author{
Richard A. Gosselin • Andreu Maldonado • \\ Greg Elder
}

Published online: 22 September 2009

(c) The Author(s) 2009. This article is published with open access at Springerlink.com

\begin{abstract}
Introduction There is a dearth of data on cost-effectiveness of surgical care in resource-poor countries. Doctors Without Borders (Médecins Sans Frontières; MSF) is a nongovernmental organization (NGO) involved in the many facets of health care for underserved populations, including surgical care. Methods A cost-effectiveness analysis (CEA) was attempted at two of their surgical trauma hospitals: Teme Hospital in Nigeria and La Trinité Hospital in Haiti. Conclusion At $\$ 172$ and $\$ 223$ per Disability-Adjusted Life-Year (DALY) averted, respectively, they are in line with other reported CEAs for surgical and nonsurgical activities in similar contexts.
\end{abstract}

\section{Introduction}

There is an increasing interest for the role of surgical care in public health in developing countries [1, 2]. It has been estimated that preventable or treatable surgical conditions account for roughly $11 \%$ of the world's total disabilityadjusted life-years (DALYs) [3]. Weiser et al. recently published their findings that differences between met and unmet

R. A. Gosselin ( $\square)$

School of Public Health, University of California Berkeley,

Berkeley, CA, USA

e-mail: froggydoc@comcast.net

A. Maldonado $\cdot$ G. Elder

Médecins Sans Frontières, Paris, France

A. Maldonado

e-mail: andreu.maldonado@gmail.com

G. Elder

e-mail: geldermd@yahoo.com surgical needs are highly disproportionate between rich and poor countries [4]. Particularly alarming is the rapid increase in the number of injuries, especially those related to road traffic crashes, which often require surgical attention, while the capacity to address them, both human and material, remains woefully inadequate in resource-poor environments [5]. The long-held public health mantra that surgery is too expensive for basic health care packages has been challenged [3, 6, 7]. Appropriate surgical care can be cost-effective. Some nongovernmental organizations (NGOs) are trying to step in where government efforts are insufficient, to support and supplement surgical activities. Médecins Sans Frontières (Doctors Without Borders; MSF) is one of the best-known international humanitarian organizations, and it has recently added surgical trauma programs to its wide spectrum of activities. The purpose of this article is to review the costeffectiveness (properly, cost-utility) of two such programs, in Nigeria and Haiti, and to compare with available data.

\section{Background}

Médecins Sans Frontières is an international, nongovernmental, humanitarian organization conducting emergency medical activities in over 60 countries. It was established in 1971 and now consists of a network of 19 national offices including five operational sections. Every year MSF sends 2,500 expatriate volunteers into the field to work alongside more than 20,000 national staff. The operational budget in 2007 exceeded $\$ 790$ million US, of which $90 \%$ was from private funds. In that same year MSF conducted 8.4 million outpatient consultations, hospitalized 340,000 patients, and carried out more than 50,000 surgical procedures. The organization's surgical activities cover a range of general to specialized activities including obstetrics, fistula, 
trauma, orthopaedic, and burns in resource-poor, conflict, and post-conflict settings.

The French operational section implements two trauma surgery programs in contexts of urban violence. La Trinité Hospital, Port Au Prince, Haiti, was opened in 2004 during an acute phase of urban warfare. The security context has gradually settled with improved political stability and the presence of a UN stabilization force MINUSTA. Teme Hospital, Port Harcourt, Nigeria, opened in late 2005 in a less acute and less structured conflict between a variety of actors, gangs, and militias in the capital of the oil-rich Niger Delta region. At these trauma centers in densely populated urban settings, inclusion triage criteria include all life-threatening traumatic injuries regardless of whether the etiology is conflict related or not. While both programs opened with the objective of reducing morbidity and mortality in civilians affected by the conflicts, they have expanded to provide access to emergency trauma surgery, with now more than $80 \%$ of admissions nonviolence related. In both cities it is possible to find trained staff and equipped facilities, but only at prohibitive cost; free, or even low-cost emergency care is simply not available.

As in most resource-poor countries, the general management of fractures is conservative: closed treatment with casts of most closed fractures, external fixation of significantly (Gustilo grade 2 and above) open fractures of long bones, and, until recently, skeletal traction for most femur fractures. For the last couple of years, MSF has been using successfully the SIGN (Surgical Instrument Generation Network) intramedullary nailing system for many long bone fractures. This was the case at both sites during the sample period.

\section{Methods}

The World Health Organization (WHO) guidelines for costeffectiveness analysis were followed as closely as possible [8]. A 3-month sample period between August and October 2008 was selected for both sites. All available records and logbooks were retrieved from the outpatient department (OPD), the operating theaters (OT), and all wards. In addition, data were collected for all admissions, surgical procedures, and outpatient encounters, including sex, age, diagnosis, treatment, mechanism of injury, and length of stay (LOS), if applicable. This is summarized in Table 1. As previously described, DALYs averted are the metric for effectiveness [6, 7]. DALYs were calculated according to the Global Burden of Disease (GBD) methodology using the discounted and age-weighted life expectancy tables (Years of Life Lost, YLL), and updated disability weights [9, 10]. DALYs averted were calculated by factoring in two more variables, both on a scale from 0 to 1 : severity of condition (probability of condition $\mathrm{X}$ of being lethal or leaving a
Table 1 Overall activity

\begin{tabular}{lll}
\hline & $\begin{array}{l}\text { Port Harcourt } \\
\text { number }(\%)\end{array}$ & $\begin{array}{l}\text { Port au Prince } \\
\text { number }(\%)\end{array}$ \\
\hline Total patients seen & 2,524 & 4,541 \\
Admissions & $711(28)$ & $499(11)$ \\
Outpatient department & $1742(69)$ & $3,905(86)$ \\
Hospital deaths & $18(2.6)$ & $26(5.2)$ \\
Left against medical advice & $25(1.5)$ & $40(0.9)$ \\
Referrals & $28(1.6)$ & $53(1.2)$ \\
\hline
\end{tabular}

Table 2 Scoring system

\begin{tabular}{ll}
\hline Severity of disease & Weight \\
$>95 \%$ fatal without TX & 1.0 \\
$<95 \%$ and $>50 \%$ & 0.7 \\
$<50 \%$ and $>5 \%$ & 0.3 \\
$<5 \%$ & 0 \\
Effectiveness of treatment & \\
$>95 \%$ chance of cure & 1.0 \\
$<95 \%$ and $>50 \%$ & 0.7 \\
$<50 \%$ and $>5 \%$ & 0.3 \\
$<5 \%$ & 0 \\
\hline
\end{tabular}

$T X$ treatment

permanent sequalae if left untreated) and success of treatment (probability of treatment $\mathrm{Y}$ of preventing death or permanent disability), as illustrated in Table 2. This method was originally described by McCord and Chowdhury [7], and it was only mildly modified for our previous studies [6, 11]. This method was informally validated internally with sensitivity analysis, but, to our knowledge, it has not been used independently.

For example, a successful laparotomy for a 20-year-old male with a penetrating abdominal wound would avert 35.02 (YLL at age 20) $\times 1$ (probability of death if untreated $>95 \%) \times 1$ (probability of treatment preventing death $>95 \%$ ) $=35.02$ DALYs averted. Treating the same 20-year-old male for a tibia fracture would avert: 35.02 $($ YLL at age 20$) \times 0.271$ (disability weight for tibia fracture) $\times 0.7$ (probability of permanent sequalae without treatment between $50 \%$ and $95 \%$ ) $\times 0.7$ (probability of treatment being successful in preventing disability between 50 and $95 \%)=4.65$ DALYs averted.

DALYs and DALYs averted were calculated for all patients at both sites, and the results are summarized in Table 3. It was assumed that all patients with major abdominal or chest injuries would have died without treatment, and that treatment was successful in preventing death, unless the patient died in the perioperative period.

Costs were divided into fixed and operating costs. Fixed costs are the result of applying standard depreciation schedules to capital investments (including physical 
Table 3 Comparative overall activity, DALYs and DALYs averted

\begin{tabular}{|c|c|c|c|c|c|c|}
\hline & \multicolumn{3}{|c|}{ Port Harcourt } & \multicolumn{3}{|c|}{ Port au Prince } \\
\hline & Cases & DALYS & DALYs averted & Cases & DALYs & DALYs averted \\
\hline Outpatient department & 1,756 & 5,872 & 1,898 & 3,905 & 13,336 & 3,554 \\
\hline Non-orthopedic & 92 & 2,084 & 1,857 & 205 & 3,631 & 2,847 \\
\hline Orthopedic & 494 & 3,557 & 1,676 & 294 & 2,024 & 976 \\
\hline Total & 2,342 & 11,513 & 5,431 & 4,404 & 18,991 & 7,377 \\
\hline
\end{tabular}

rehabilitation work, medical and other equipment, cars, etc.). Operating costs are based on data extracted from MSF's internal accountancy, reflecting actual figures. Costs for drugs and medical material were obtained from the pharmacy management software rather than from accountancy, in order to reflect actual consumption within the study's interval. Costs were converted to US\$ using conversion rates prevalent at the time: $1 \$ \mathrm{WS}=0.68$ Euro $=11.84$ Nigerian Nairas $=40$ Haitian Gourdes . Table 4 summarizes costs for the two sites evaluated in this study.

\section{Results}

The MSF-TEME hospital has 70 beds, including 7 "ICU" beds in OPD, It employs, on average 10 expatriates and 227 nationals (131 care providers and 96 support personnel). Port Harcourt does not have a formal pre-hospital care

Table 4 Comparative costs (\$US) for July-September 2008 period

\begin{tabular}{lcc}
\hline & Port Harcourt & Port au Prince \\
\hline Fixed costs & & \\
Medical & 82,023 & 65,311 \\
Logistics & 15,537 & 19,323 \\
Cars & 8,709 & 10,643 \\
Operating costs & & \\
International staff (salaries/benefits) & 127,770 & 130,768 \\
National staff (salaries/benefits) & 450,324 & 966,947 \\
Office running costs & 21,405 & 4,553 \\
Equipment and consumables & 33,057 & 40,309 \\
Drugs & 67,914 & 211,495 \\
International transport & 22,050 & 49,524 \\
Maintenance & & \\
Infrastructure and equipment & 14,715 & 13,772 \\
Hospital fuel & 20,607 & 37,063 \\
Fuel \& transportation & 32,064 & 13,029 \\
Rent & 35,169 & 30,757 \\
Miscellaneous & & \\
Training, consultancy & 1,551 & 49,305 \\
Total & 932,895 & $1,642,799$ \\
\hline
\end{tabular}

system. The few ambulances services available are costly and are in fact only glorified taxis, as no pre-hospital care is provided, other than transportation. Family or friends in personal cars, taxis, or motorbikes, bring the vast majority of patients. Data were insufficient to assess the average trauma-admission delay. During the sample period, there were 51 life-saving procedures, the vast majority of them done during daytime, as night travel is often prohibited for the expatriate staff due to security concerns. Bed occupancy was $78 \%$ in July, $87 \%$ in August, and 90\% in September for an average of $85 \%$ for the sample period, all by trauma patients. Of interest is the fact that salaries and benefits for the national staff represent $48.3 \%$ of all expenses. A total of 2,524 patients were seen, 711 of which (28\%) were admitted (586 new admissions and 125 readmissions). Typically, DALYs and DALYs averted are not attributed to re-admissions, even if they contribute to costs, as their burden has already been counted at the initial encounter. There was a total of 18 deaths $(2.6 \%$ hospital mortality), $28(1.6 \%)$ patients were referred elsewhere for treatment, and $25(1.5 \%)$ left against medical advice (AMA). We calculated that, for the sample period, the hospital faced a total burden of 11,513 DALYs, of which 5,431 were averted by treatment. Dividing the costs for the sample period by the sum of all DALYs averted gives a cost-effectiveness ratio of $\$ 172$ per DALY averted.

The MSF surgical activity in Haiti is divided into two separate sites. La Trinité hospital, and Pacot rehabilitation center. The Trinité hospital had 60 beds during the sample period: 9 ICU beds, 18 for burn patients and 33 for "visceral" and orthopedic patients. It has three functioning operating theaters. As in Port Harcourt, Port au Prince does not have a formal pre-hospital trauma care system. Most patients are brought in regular civilian vehicles. During the sample period, security issues in Port au Prince were not as sever as in Port Harcourt, and of the 79 life-saving procedures performed, almost half were at night. Here again, data did not allow calculation of the injury-admission interval. Bed occupancy was $87 \%$ in July and September and $84 \%$ in August, for an average of $86 \%$. Contrary to $\mathrm{PH}$, burns are among the admission criteria at Trinité. There are 214 full time employees at Trinité, including 5 expatriates: 137 care providers, including 22 national physicians, and 
77 support personnel. Pacot has 48 beds (40 adults and 8 pediatrics) used exclusively for patients transferred from La Trinité. It has 96 employees, including 3 expats and 93 nationals. 63 of them are directly involved in patient care, and 33 are support personnel, including administration. Average bed occupancy for the sample period was $95 \%$. So Trinité and Pacot effectively function as a 108-bed hospital, located on two separate campuses, with a total of 310 employees. New patients are not seen at Pacot, and therefore there are no new DALYs averted by treatment. Here, salaries and benefits to national staff represent $59 \%$ of all costs. A total of 4,541 patients were seen, with $499(11 \%)$ being admitted and 3,905 (86\%) being treated as outpatients. There were 18 deaths in the OPD, and 26 deaths after admissions, for an overall hospital mortality of $5.2 \%$. A total of 40 patients $(0.9 \%)$ left against medical advice, and 58 patients $(1.2 \%)$ were referred elsewhere for specialized care. The remaining 4,404 patients represented a potential burden of 18,991 DALYs, 7,377 of which were averted by treatment. Dividing the total costs of the activity by the total DALYs averted gives a cost-effectiveness ratio of $\$ 223$ per DALY averted.

\section{Discussion}

The literature on CEAs for surgical activities in developing countries is sparse. McCord et al. showed a $\mathrm{C} / \mathrm{E}$ ratio of \$11/DALY averted in their obstetrical hospital in Bangladesh. Cesarean sections often save the lives of both a young mother and a newborn, thus averting many more DALYs than procedures aimed at preventing disability [7]. In Sierra Leone, a hospital with a mixture of pediatrics, general surgery, and orthopedic surgery, both emergent and elective, had a C/E ratio of around \$38/DALY averted [11]. It was not possible to completely disaggregate the medical and surgical activities and their associated costs, but it is reasonable to assume that the surgical activity alone would be significantly higher than \$38/DALY averted. In Battambang, Cambodia, a similar study done in a hospital solely dedicated to trauma, like those in Port Harcourt and
Port au Prince, had a C/E ratio of around \$78/DALY averted [6]. Comparisons are fairer as all three sites have more or less the same patient population. In Cambodia, because outpatient records were unusable, DALYs averted were not attributed to the OPD activity, whereas they represent $35 \%$ and $48 \%$ of all DALYs averted in Port Harcourt and Port au Prince, respectively. The true $\mathrm{C} / \mathrm{E}$ ratio in Battambang is thus significantly lower than $\$ 78$ / DALY averted, increasing even more the apparent differences between sites.

By far the biggest drivers behind these differences are the different pay scales and benefits for national staff. The 182 Cambodian national staff salaries and benefits account for only $23 \%$ of all costs. With a bed occupancy of $100 \%$ and 1.72 national staff per active bed, at an average monthly salary of $\$ 130$, the Battambang hospital operates at much lower costs than Port Harcourt, where average bed occupancy is $85 \%$, with 3.79 national staff per active bed at a monthly average salary and benefits of $\$ 534$, and than Port au Prince, with an average bed occupancy of $86 \%$, 3.25 national staff per active bed at an average $\$ 1,068$ per month. If national staff salaries and benefits are adjusted to represent $23 \%$ of costs, the $\mathrm{C} / \mathrm{E}$ ratio drops to $\$ 116$ per DALY averted in Port Harcourt, and $\$ 119$ per DALY averted in Port au Prince. Most of the remaining differences with Battambang relate to fixed costs: the ownership model used in Cambodia, amortized over 30 years or depreciated on a 7-year schedule, lowers monthly fixed costs considerably compared with the rentorship model favored by MSF. There are valid philosophical and operational arguments behind both approaches, reflecting different organizational models and directions. Table 5 includes data from the previously published series in Cambodia to compare certain effectiveness and costeffectiveness indicators. Compared to the Battambang study, both MSF sites treat more patients with more severe illnesses, and they avert overall more DALYs per admission and more DALYs per active bed. DALYs averted per admission can be used as a proxy measure of injury severity, illustrating the type of trauma seen in these MSF programs.

Table 5 Comparative effectiveness indicators

\begin{tabular}{|c|c|c|c|}
\hline & Battambang & Port Harcourt & Port au Prince \\
\hline National staff per active bed & 1.72 & 3.79 & 3.25 \\
\hline$\%$ of total costs for national staff salaries & $23 \%$ & $48 \%$ & $59 \%$ \\
\hline Monthly turnover ratio (patient per active bed) & 3.00 & 3.95 & 1.79 \\
\hline Cost-effectiveness ratio (\$/DALY averted) & 78 & 172 & 233 \\
\hline Adjusted cost-effectiveness ratio (for national staff salaries) (\$/DALY averted) & 78 & 116 & 119 \\
\hline DALYs averted per admission & 3.96 & 6 & 7.7 \\
\hline DALYs averted per active bed & 35.8 & 58.9 & 41.6 \\
\hline
\end{tabular}


The differences in costs and cost-effectiveness between Port Harcourt and Port au Prince are also mainly attributable to the different pay scales and benefits for national staff. When adjusting the percentage of total costs from salaries/benefits to national staff in Port au Prince (59\%) to the level in Port Harcourt (48\%), the cost per DALY averted in Port au Prince falls to \$176, almost identical to that in Port Harcourt. The Port au Prince situation has an added relative inefficiency in that its activity is split between two different sites, creating redundancies and increasing costs without impact on effectiveness. Furthermore, burn management, done in Port au Prince, but not in Port Harcourt, is known to be a costly and lengthy proposal, as shown by the lower monthly turnover ratio (patient per active bed): 1.79 in Port au Prince compared to 3.95 in Port Harcourt and 3.0 in Battambang. The treatment of burns, which averts only $0.5 \%$ of total DALYs, very likely represents more than $0.5 \%$ of all costs, considering prolonged LOS, supplies and manpower.

On an annualized basis, the Port Harcourt activity prevents 21,724 years of premature death or disability, and that in Port au Prince, 29,508 years. This translates, on a yearly basis, into roughly avoiding one year of less than healthy life for 50,000 people, or 10 years for 5,000 people, etc.

There are numerous potential biases affecting such a study, including seasonal sampling, misclassification, and the necessary and arbitrary nature of weighting the likelihood of outcomes with and without treatment. In particular, the scoring system is still awaiting external validation. Nevertheless, the consistency of the methods allows valid comparisons between sites, even if absolute accuracy is debatable. Comparisons with other studies for different interventions in different contexts need to be made much more cautiously. Still, the C/E ratios at Port Harcourt and Port au Prince are not out of line compared to recently published figures for more conventional public health activities: $\$ 540$ per DALY averted for rotavirus vaccination in Vietnam [12], \$53 per DALY averted (95\% CI \$18\$306) for a therapeutic feeding program in Zambia [13], around \$200 per DALY averted (\$154-\$252) for pneumococcal conjugated vaccination in Latin America [14], and around $\$ 400$ per DALY averted ( $\$ 260-\$ 530)$ for ARV treatment in TB patients [15].

\section{Conclusions}

Even when considering the numerous potential biases, the surgical care of injuries at these two MSF sites appears to be cost-effective. Avoiding a total of 50,000 DALYs a year is a significant contribution. This should strengthen the argument that surgical management of injuries is not too expensive to be included in basic health care packages for resource-poor countries, especially considering the actual and predicted rise in need. It is hoped that this study can provide more data to inform decision makers at all levels.

Open Access This article is distributed under the terms of the Creative Commons Attribution Noncommercial License which permits any noncommercial use, distribution, and reproduction in any medium, provided the original author(s) and source are credited.

\section{References}

1. Bickler S, Spiegel D (2008) Global surgery-defining a research agenda. Lancet 372:90-92

2. Farmer PE, Kim JY (2008) Surgery and global health: a view from beyond the OR. World J Surg 32:533-536

3. Debas H, Gosselin RA, McCord C (2006) Surgery. In: Jamison D et al (eds) Disease control priorities in developing countries. Oxford University Press, Washington, pp 1245-1260

4. Weiser TG, Regenbogen SE, Thompson KD et al (2008) An estimation of the global volume of surgery: a modeling strategy based on available data. Lancet 372:139-148

5. Kingham TP, Kamara TB, Cherian MN et al (2009) Quantifying surgical capacity in Sierra Leone: a guide for improving surgical care. Arch Surg 144:122-127

6. Gosselin RA, Heitto M (2008) Cost-effectiveness of a district trauma hospital in Battambang, Cambodia. World J Surg 32:2450-2453

7. McCord C, Chowdhury Q (2003) A cost effective small hospital in Bangladesh: what it can mean for emergency obstetric care. Int J Gynaecol Obstet 81:83-92

8. Tan Torres-Edejer T, Baltussen R, Adam T et al (2003) WHO guidelines to cost-effectiveness analysis. World Health Organization, Geneva

9. Jamison D, Breman J, Measham A et al (eds) (2006) Disease control priorities in developing countries. Oxford University Press, Washington, DC

10. Murray CJL, Lopez AD (eds) (1996) The global burden of disease. Harvard University Press, Boston

11. Gosselin RA, Thind A, Bellardinelli A (2006) Cost/DALY averted in a small hospital in Sierra Leone: what is the relative contribution of different services? World J Surg 30:505-511

12. Kim SY, Goldie SJ, Salomon JA (2009) Cost-effectiveness of rotavirus vaccination in Vietnam. BMC Public Health 9:29

13. Bachmann MO (2009) Cost effectiveness of community-based therapeutic care for children with severe acute malnutrition in Zambia: decision tree model. Cost Eff Resour Alloc 7:2

14. Sinha A, Constenla D, Valencia JE et al (2008) Cost-effectiveness of pneumococcal conjugate vaccination in Latin America and the Caribbean: a regional analysis. Rev Panam Salud Publica 24:304-313

15. Currie CS, Floyd K, Williams BG et al (2005) Cost, affordability and cost-effectiveness of strategies to control tuberculosis in countries with high HIV prevalence. BMC Public Health 12:130 